\title{
Quantification of Chaoborus and small fish by mobile upward-looking echosounding
}

\author{
Roman BARAN, $, 1,2$ Michal TUŠER, ${ }^{1}$ Helge BALK, ${ }^{1,3}$ Petr BLABOLIL, ${ }^{1}$ Martin ČECH, ${ }^{1}$ Vladislav DRAŠTÍK, ${ }^{1}$ \\ Jaroslava FROUZOVÁ, ${ }^{1}$ Tomáš JƯZA, ${ }^{1}$ Ievgen KOLIADA, ${ }^{1}$ Milan MUŠKA, ${ }^{1}$ Zuzana SAJDLOVÁ, ${ }^{1}$ Lukáš VEJŘÍK, ${ }^{1}$ \\ Jan KUBEČKA ${ }^{1,2^{*}}$
}

${ }^{1}$ Institute of Hydrobiology, Biology Centre of the Czech Academy of Sciences, České Budějovice, Czech Republic; ${ }^{2}$ Faculty of Science, University of South Bohemia, České Budějovice, Czech Republic; ${ }^{3}$ Department of Physics, University of Oslo, Norway

\begin{abstract}
Chaoborus larvae inhabit frequently the water column of lakes, when they can be mistaken for small fish. Because larvae ascend up to the blind zone of downward-looking echo sounding at night, quantitative acoustic estimation of them is possible only with upwardlooking approach. For this reason, the mobile hydroacoustic upward-looking system (120 and $38 \mathrm{kHz}$ split-beam echosounder) in combination with a direct catch method (trawling) was tested to investigate the night community of invertebrates and juvenile fish in the surface layer of the Rímov reservoir (Czech Republic). In the target strength range of invertebrates (smaller than -59 dB), the 38 $\mathrm{kHz}$ echosounder recorded only a small proportion of targets while the $120 \mathrm{kHz}$ echosounder recorded distinct peaks corresponding to high densities of Chaoborus (target strength, TS range -70 to $-60 \mathrm{~dB}$, average TS -66 to $-64 \mathrm{~dB}$ ). At $120 \mathrm{kHz}$ frequency, the TS distribution of smaller cohort of juvenile fish ( $<25 \mathrm{~mm}$ in length) overlapped the TS-distribution of Chaoborus. The number of these smaller juvenile fish was so small compared with the number of Chaoborus that they did not seriously bias acoustic Chaoborus estimate. The correlation between the density of Chaoborus with small contamination of juvenile fish larvae from trawling and acoustic recording made with the $120 \mathrm{kHz}$ echosounder was high $\left(\mathrm{R}^{2}=0.88\right)$, but the acoustic densities from trace counting appeared to underestimate Chaoborus abundance when the density was $>1.5$ ind. $\mathrm{m}^{-3}$.
\end{abstract}

\section{INTRODUCTION}

Hydroacoustics is a well-established method for assessing the parameters of fish stock in the sea and in fresh water (Simmonds and MacLennan, 2005). Even small fish can be detected (Frouzová and Kubečka, 2004) but problems arise when larvae of phantom midge (Chaoborus sp.) and juvenile fish occur in the same habitat (Malinen et al., 2005; Knudsen et al., 2006). In stratified lakes, targets of interest often occur only a few centimeters to a few meters under the surface and, for this reason, the downward-looking approach does not provide reliable data near the surface and is often

Corresponding author: kubecka@hbu.cas.cz

Key words: К̌ímov reservoir; juvenile fish; invertebrate; trawling; hydroacoustics; target strength.

Edited by: Pietro Volta, CNR-IRSA Verbania, Italy

Received: 7 June 2018.

Accepted: 29 November 2018.

This work is licensed under a Creative Commons Attribution NonCommercial 4.0 License (CC BY-NC 4.0).

CCopyright R. Baran et al., 2018

Licensee PAGEPress, Italy

J. Limnol., 2019; 78(1): 60-70

DOI: 10.4081/jlimnol.2018.1837 replaced by horizontal echo sounding. Upward-looking system makes it possible to record small targets in the near surface layer and to accurately determine their size (Baran et al., 2017).

The phantom midge Chaoborus sp. (Diptera, family Chaoboridae) spend most of its life cycle in water (Burrows and Dorosenko, 2014). Chaoborus larvae eliminate the risk of predation from planktivorous fish by performing diel vertical migrations, spending the day in the hypolimnion or sediment and at night ascending to the epilimnion (Voss and Mumm, 1999; Lagergren et al., 2008). For buoyancy regulation, Chaoborus larvae have two pairs of air sacs (Teraguchi, 1975), which acoustically produce similar echoes as strong as juvenile fish (Eckmann, 1998). Consequently, the night time copresence of Chaoborus larvae with small fish may cause significant errors in acoustic estimates of juvenile fish (Eckmann, 1998; Vinni et al., 2004; Malinen et al., 2005).

The simplest and most widely used approach is to consider the echoes from small targets as reverberation and to eliminate their contribution to the total echo integral by thresholding (Simmonds and MacLennan, 2005). For poor signal-to-noise conditions, this principle was improved considerably by Eckmann (1998) based on stepwise thresholding and the allocation of echointegrator output to acoustically smaller Chaoborus and larger fish. This method can be used in dense Chaoborus aggregations when co-occurring targets are of clearly distinct sizes. However, use of target strength (TS) where possible (in lower densities when single targets can be 
distinguished) should provide a more direct distinguishing of Chaoborus and fish.

The bias produced by the inclusion of Chaoborus in fish estimates is apparently dependent on echosounder frequency. Jones and Xie (1994) reported that the strongest echo of Chaoborus can be recorded by an echosounder using a frequency of $225 \mathrm{kHz}$, due to better sensitivity of higher frequencies. Similarly, Knudsen et al. (2006) found that the best frequency for studying of Chaoborus larvae is $200 \mathrm{kHz}$.

Our work was concentrated on $120 \mathrm{kHz}$, a very common frequency for studying fish in lakes and reservoirs (Simmonds and MacLennan, 2005; CEN, 2014; Draštík et al., 2017). The aim of this study was to disentangle the acoustic record of the pelagic invertebrate community dominated by Chaoborus mixed with small fishes using two contrasting echosounder frequencies of 120 and $38 \mathrm{kHz}$. The paper aims to fill the knowledge gap on target strength of Chaoborus specifically for the 120 $\mathrm{KHz}$ frequency widely used in fisheries surveys. We analyzed size distributions and abundances of non-fish and fish targets and compared acoustic results with a direct capture method.

\section{METHODS}

This study was conducted in the Rímov Reservoir (48 $50^{\prime}$ N, 19³0’E, $471 \mathrm{~m}$ asl, Fig. 1), $170 \mathrm{~km}$ south of Prague, Czech Republic. The reservoir was constructed on the Malše River in 1978. It is a canyon-shaped reservoir with a total length of $13 \mathrm{~km}$, a maximum volume of $33 \times 10^{6} \mathrm{~m}^{3}$, a surface area of $2.1 \mathrm{~km}^{2}$, and an average and maximum depth of $16 \mathrm{~m}$ and $43 \mathrm{~m}$, respectively. The trophic state of the reservoir is mesotrophic to eutrophic with well-developed thermal stratification during the summer. Dominant fish are common bream (Abramis brama Linnaeus, 1758), roach (Rutilus rutilus Linnaeus, 1758) and bleak (Alburnus alburnus Linnaeus, 1758). These species frequently occur in open water of the reservoir during the first year of life (Jůza et al., 2009, 2013). Chaoborus larvae are not abundant (Řiha et al., 2015) and were observed to form scattering layers in the hypolimnion during the day ascending to the surface at night (Čech and Tušer, personal communication).The pelagic habitat of the reservoir was investigated using mobile hydroacoustics and trawling over the course of two nights, 23/24 July (N1) and 8/9 August (N2) in 2014

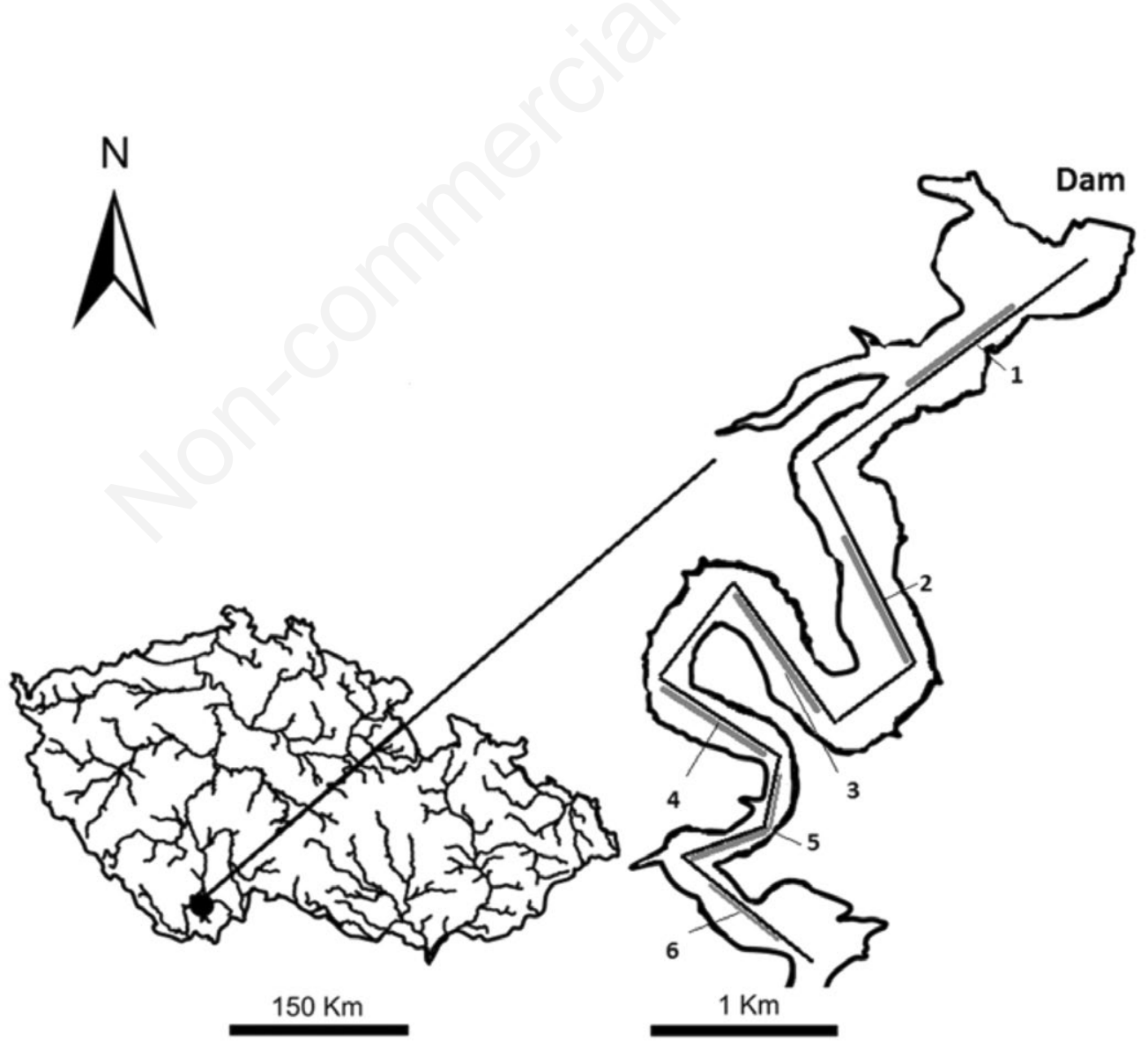

Fig. 1. A map of the Rímov Reservoir and its location in the Czech Republic. The black line shows the trajectory of the mobile upwardlooking survey, and the gray line indicates the trawl sampling in depth 0-2 m (upstream) and 3-5 m (downstream). 
with slightly different stratification conditions (Fig. 2).

The acoustic part of the study was performed using a newly developed method based on a mobile upwardlooking acoustic system (Baran et al., 2017). A research vessel (11 m long with a $210 \mathrm{HP}$ engine) was equipped with two $12 \mathrm{~m}$ long submersible arms on either side that held a tiltable platform with attached transducers between their front ends. During the acoustic survey, the arms submerged the platform to a depth of $8 \mathrm{~m}$ with transducers emitting towards the surface. An exact vertical position of the acoustic beam was measured using an electronic clinometer, the RIEKER H5A1-90 (RIEKER Inc. USA).

Frequencies of $120 \mathrm{kHz}$ (circular split-beam transducer SIMRAD ES120-7G with a nominal angle of 7 degrees) and $38 \mathrm{kHz}$ (circular split-beam transducer SIMRAD ES38-12 with a nominal angle of 12 degrees) were used in the study. The operating power of the 120 and $38 \mathrm{kHz}$ echosounder was set to $100 \mathrm{~W}$ with $0.05 \mathrm{~s}$ pulse interval $\left(20\right.$ ping s$\left.^{-1}\right)$ and the pulse length was set to $128 \mu \mathrm{s}$ and $256 \mu \mathrm{s}$ for $38 \mathrm{kHz}$. Before each survey, both transducers were calibrated using a 33.2 tungsten-carbide sphere for $120 \mathrm{kHz}$ and a $60 \mathrm{~mm}$ diameter copper sphere for $38 \mathrm{kHz}$ calibration as described by Foote et al. (1987).

The acoustic survey was performed in straight-line transects at a constant speed of $1 \mathrm{~m} \cdot \mathrm{s}^{-1}$ following the original river valley (Fig. 1). To avoid striking the bottom with the submerged platform, only the deepest part (depth $>10 \mathrm{~m}, 6 \mathrm{~km}$ long zone from the dam) of the reservoir was sampled. Acoustic recordings started from the dam one hour after sunset (approximately at 22:30) and finished upstream in the middle part of the reservoir (approximately at 0:30). Recording was then stopped in the middle part of reservoir, and after a half hour waiting period (to avoid bubbles made by the boat propellers), the same transects were sampled downstream (from the middle part to the dam finished approximately at 3:45 a.m.). The GPS coordinates of the survey cruise was measured using a Garmin GPSMAP 60CSx GPS handheld connected to an external antenna for better reception of the signal.

Raw acoustic data were analyzed using the Sonar5Pro post-processing software (Lindem Data Acquisition, Oslo, Norway). Beyond the theoretical blind zone (half of the pulse length from the phase boundary - water surface), we defined a line of $0.1 \mathrm{~m}$ and $0.2 \mathrm{~m}$, for the 120 $\mathrm{kHz}$ and $38 \mathrm{kHz}$ echosounders, respectively, below the detected surface so the surface echoes were safely excluded from data processing prior to data analysis. The acoustic data were divided into two depth layers according to layers sampled by trawl depths $(0-2 \mathrm{~m}$ and 3-5 m below the surface, without defined line 0.1 or 0.2 $\mathrm{m})$. An automatic single echo detection was set up to accept targets between lower and upper thresholds for 70 to $-49 \mathrm{~dB}$ (corresponding to a theoretical fish length of about $0.5-60 \mathrm{~mm}$ for small perch calculated for the frequency $120 \mathrm{kHz}$ using the TS length relationship of Frouzová and Kubečka (2004). The same regression was used to convert captured fish lengths to TS from the 120 $\mathrm{kHz}$ echosounder. To convert the captured fish size to the TS from the $38 \mathrm{kHz}$ echosounder the regression by Love (1977) was used. A valid track was defined as at least two subsequent single echoes from the same target, separated by a maximum of one missing ping within a $0.1 \mathrm{~m}$ vertical range gate.

Acoustic tracks abundance was calculated according

\section{Temperature $\left({ }^{\circ} \mathrm{C}\right)$}

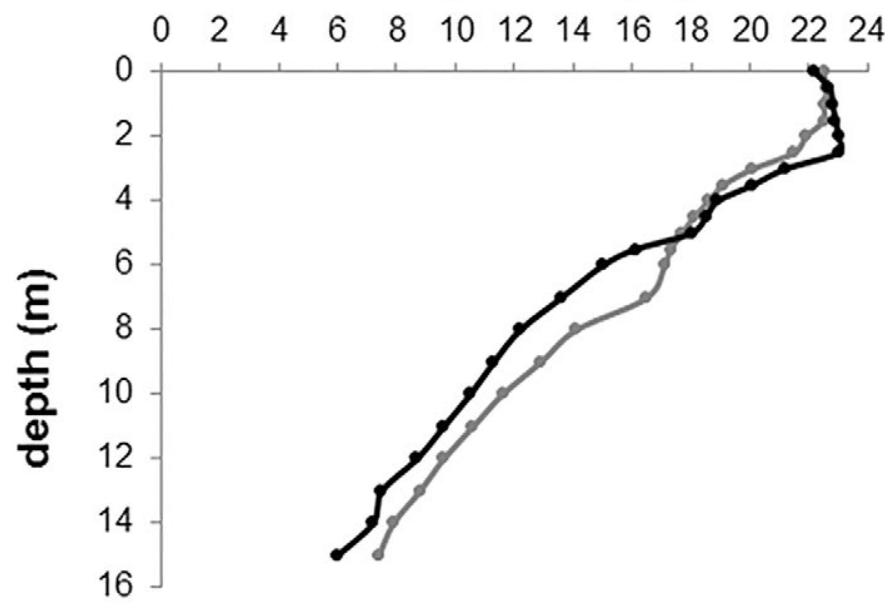

Dissolved oxygen (mg.L-1)

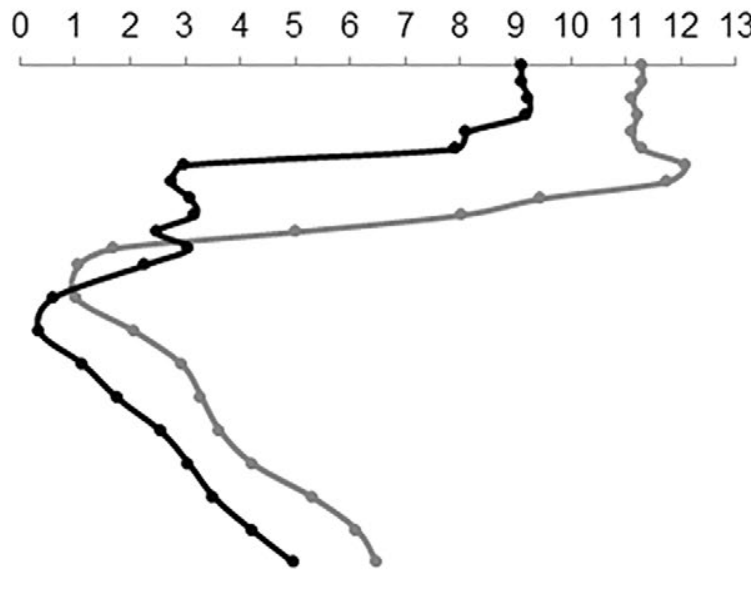

Fig. 2. Vertical profile of water temperature and dissolved oxygen. The gray lines indicate measurements for night 1 and black for night 2. 
to the track counting method (Simmonds and MacLennan, 2005; CEN, 2014):

$$
\left(\mathrm{f} / \mathrm{m}^{3}\right)_{\text {tracks }}=\text { tracks } / \mathrm{v}_{\mathrm{w}}
$$

where tracks stands for the number of tracks in a given transect and it is divided by the sampled wedge volume $\mathrm{v}_{\mathrm{w}}$ in $\mathrm{m}^{3}$. Abundance was separately expressed as the number of tracks in $100 \mathrm{~m}^{3}$ of sampled water $\left(\mathrm{f} / 100 \mathrm{~m}^{3}\right)$ for the 0-2 and 3-5 $\mathrm{m}$ depth layers. The tracks larger than $-55 \mathrm{~dB}$ were considered to represent fish only while targets within the TS range of -70 to $-55 \mathrm{~dB}$ were considered a mixture of air containing invertebrates and the smallest fish from summer spawning

Sampling of the pelagic habitat was performed using a fixed frame ichthyoplankton trawl (mouth opening $2 \times 2$ $\mathrm{m}$, mesh size $1 \mathrm{~mm} \times 1.35 \mathrm{~mm}$ ) with the collecting bucket at the end (Jůza et al., 2010). The trawl was towed for 5 min approximately $100 \mathrm{~m}$ behind a research vessel (with $15 \mathrm{HP}$ engine power) at a speed of $1 \mathrm{~m} \mathrm{~s}^{-1}$. Sampling was performed in two layers differing by oxygen and thermal conditions (0-2 m and 3-5 m, Fig. 2). The shallower depth was sampled during the upstream cruise and the deeper depth during the downstream cruise. All trawling tows began approximately $10 \mathrm{~min}$ after the acoustic survey and were hauled in parallel trajectories with the acoustic trajectories, with a total of six ichthyoplankton tows made per one depth layer (Fig. 1). For each trawl tow, the sampled water volume was calculated based on the trajectory tow distance measured by GPS, and the CPUE (catch per unit effort) of the trawl tow was expressed as catch per $100 \mathrm{~m}^{3}$ of water sampled.

Samples were immediately euthanized using a lethal dose of MS 222 and then preserved in a 4\% formaldehyde solution. In the laboratory, samples were examined under a stereoscope (Lomo MBC-10) to categorize the caught objects into Chaoborus larvae, Chaoborus pupae, other invertebrates (Chironomidae larvae, Chironomidae pupae, Hydracarina, Branchiura) and juvenile fish. Chaoborus larvae and pupae were counted, and body lengths (excluding the anal papillae) of 120 random individuals of each night and depth of both groups were measured to the nearest $\mathrm{mm}$. Other invertebrates were also counted and in 60 randomly chosen individuals body length of each category was measured to the nearest $\mathrm{mm}$. The resulting size structure was used for all counted individuals in the same depth and night. juvenile fish were counted and total length (TL) was measured to the nearest $\mathrm{mm}$.

Differences in size structures of Chaoborus were used in a paired $t$-test. Differences in the abundance estimated by ichthyoplankton trawling and hydroacoustics sampling were separately compared using the Kolmogorov Smirnov paired test for both depth layers. Additionally, the abundance estimates for both methods were regressed against each other to determine if the slope parameter was significantly different from 1 (Taskinen and Warton, 2013). Statistical analyses were carried out using the $R$ software (R Development Core Team, 2015).

\section{RESULTS}

\section{Upward-looking hydroacoustics record}

During acoustic surveys, the $120 \mathrm{kHz}$ frequency echosounder recorded 8672 and 1068 tracks in the $0-2 \mathrm{~m}$ and 3-5 m layer, respectively (sampling volume 12,514 and $8046 \mathrm{~m}^{3}$ ), while the $38 \mathrm{kHz}$ frequency observed 766 and 486 tracks for the given layers (sampling volume 20,837 and $13,382 \mathrm{~m}^{3}$ ).

During both nights, a distinct peak of all tracks between -70 and $-60 \mathrm{~dB}$ TS was recorded by the $120 \mathrm{kHz}$ system especially at the $0-2 \mathrm{~m}$ depth range, peaking at $64 \mathrm{~dB}$ at night 1 and $-65 \mathrm{~dB}$ at night 2 (Fig. 3). Using the regression from Frouzová and Kubečka (2004), this corresponds to the theoretical fish length (TL) of 10 and $9 \mathrm{~mm}$ respectively. At the 3-5 $\mathrm{m}$ depth range the targets were less abundant. The peak of TS at the depths of 3-5 $m$ was $-66 \mathrm{~dB}$ for night 1 and $-67 \mathrm{~dB}$ for night 2 , which correspond to the theoretical fish length 9 and $8 \mathrm{~mm}$ respectively.

On the contrary, the $38 \mathrm{kHz}$ echosounder recorded much fewer tracks without a distinct peak as expected from the previous results of the $120 \mathrm{kHz}$ frequency $(-70$ to $-60 \mathrm{~dB}$, Fig. 4). At night 1 in the $0-2 \mathrm{~m}$ depth the most abundant size group of tracks was recorded in the range of juvenile sizes -51 to $-49 \mathrm{~dB}$. The situation was similar for night 2 , again at $0-2 \mathrm{~m}$ depth, when tracks -50 and -49 dominated. In the 3-5 m depth layer the track abundance was lower, and TS-distribution was bimodal two peaks were clearly visible in the frequency distribution for both nights (Fig. 4).

\section{Ichthyoplankton trawl catch}

In twelve hauls during two different nights we caught 18,119 and 4683 invertebrates at the depth of $0-2 \mathrm{~m}$ and 3$5 \mathrm{~m}$ respectively (sampling volume 12,928 and 14,982 $\mathrm{m}^{3}$ ). Chaoborus larvae showed a much higher density by one or two orders of magnitude compared to fish (Tab. 1). The total catch of juvenile fish in 12 hauls was 498 and 159 individuals for the two depth strata respectively. Chaoborus larvae and pupae dominated at the surface representing more than 90 percent of the whole catch, while at the deeper layer they only constituted around 50-70 percent of the total catch (Tab. 2). At the 3-5 m depth, a significantly higher number of Hydracarina and Chironomidae larvae were recorded for night 2 (N 2, Tab. 2).

The mean size of Chaoborus larvae at the surface was $9.5 \mathrm{~mm}$ for $\mathrm{N} 1$ (Tab. 3) and $9.0 \mathrm{~mm}$ in all other samples. 
The Chaoborus larvae were significantly smaller for $\mathrm{N} 2$ (paired $t$-test, $\mathrm{df}=119, \mathrm{P}<0.05$ ) at the surface and also at the 3-5 $\mathrm{m}$ depth (paired $t$-test, $\mathrm{df}=119, \mathrm{P}<0.05$ ). Chaoborus pupae were the same sizes among nights and layers $(6.0 \mathrm{~mm})$ with the exception of slightly larger individuals in the deeper layer for night 1 (6.5 mm;
Tab. 3). The Chironomidae larvae were about $9.0 \mathrm{~mm}$ long on $\mathrm{N} 1$, but in the deeper layer and on $\mathrm{N} 2$, they were smaller ( $8 \mathrm{~mm}$, Tab. 3). Fig. 5 illustrates the size structure of the entire catch of invertebrates in the ichthyoplankton trawl.

The size distribution of juvenile fish can be divided

Tab. 1. Abundance of trawl catch $\left(\mathrm{N} .100 \mathrm{~m}^{-3}\right)$.

\begin{tabular}{|c|c|c|c|c|c|c|c|c|}
\hline & & $\mathrm{Ch}$ & larvae & & & & & \\
\hline & & & & & & & & \\
\hline & 0-2 m & 3-5 m & $0-2 \mathrm{~m}$ & $3-5 \mathrm{~m}$ & 0-2 m & 3-5 m & $0-2 \mathrm{~m}$ & 3-5 m \\
\hline Zone 1 & 69.2 & 67.3 & 156.6 & 3.9 & 2.6 & 1.6 & 1.1 & 0.2 \\
\hline Zone 2 & 177.7 & 75.3 & 79.8 & 5.2 & 4.0 & 0.7 & 0.6 & 0.6 \\
\hline Zone 3 & 210.0 & 6.0 & 77.7 & 7.7 & 5.9 & 1.9 & 1.2 & 0.7 \\
\hline Zone 4 & 84.1 & 4.6 & 138.7 & 3.6 & 3.9 & 1.1 & 2.5 & 1.0 \\
\hline Zone 5 & 52.2 & 5.0 & 36.5 & 4.5 & 10.9 & 1.5 & 3.0 & 1.1 \\
\hline Zone 6 & 39.6 & 10.7 & 46.1 & 1.1 & 7.1 & 1.6 & 7.5 & 0.9 \\
\hline
\end{tabular}
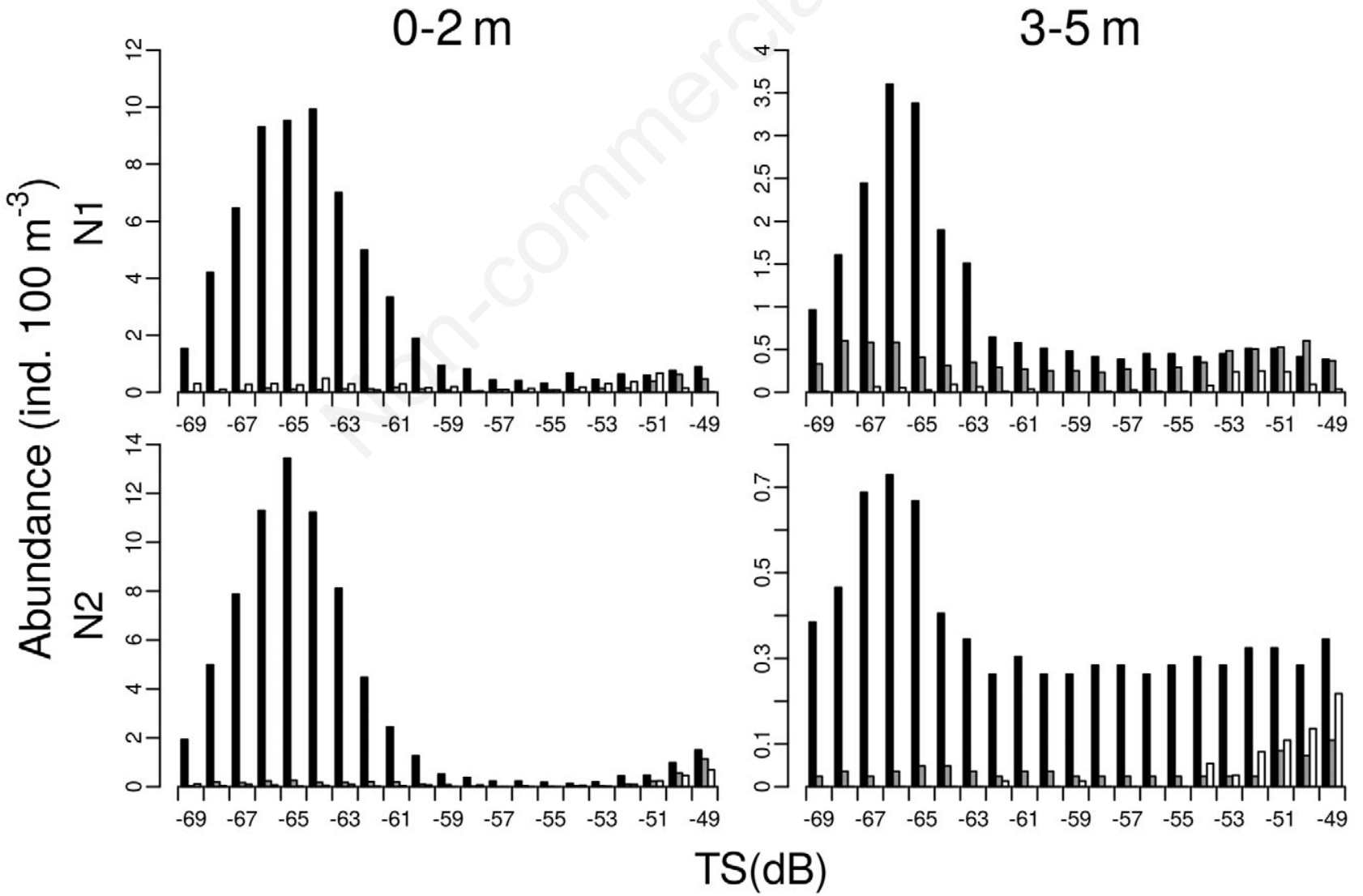

Fig. 3. TS distributions by $120 \mathrm{kHz}$ echo sounder (black), TS distribution by $38 \mathrm{kHz}$ echo sounder (grey) and TS distributions of fish converted into TS for the frequency of $120 \mathrm{kHz}$. from trawl catch (white). All values are average values over the six zones in Tab. 1. $\mathrm{N} 1$, night $1 ; \mathrm{N} 2$, night 2. 
into two cohorts. The first $(6-20 \mathrm{~mm})$ consisted most probably of fish from late summer spawning of bleak and perch. The other $(30-50 \mathrm{~mm})$ presumably corresponds to roach and bream from the ordinary spring spawning (Fig. 6). The smallest fish were primarily recorded near the surface during night 1 . During night 2 there were significantly fewer numbers in the first cohort, while the second cohort of juvenile fish grew by $10 \mathrm{~mm}$ (40-60 $\mathrm{mm})$. At the 3-5 $\mathrm{m}$ depth, the number of juvenile fish in the first cohort was lower than at the surface, and during night 2 only a few individuals of the smaller cohort were recorded.

Tab. 2. Percental proportion of invertebrates and fish contribution in the trawl catch. Total number of invertebrates and fish 11,980 and 6298 at N1 and N2.

\begin{tabular}{|c|c|c|c|c|c|c|c|c|}
\hline \multirow[t]{3}{*}{ Category } & \multicolumn{4}{|c|}{ Night 1} & \multicolumn{4}{|c|}{ Night 2} \\
\hline & \multicolumn{2}{|c|}{ Depth 0-2 m } & \multicolumn{2}{|c|}{ Depth 3-5 m } & \multicolumn{2}{|c|}{ Depth 0-2 m } & \multicolumn{2}{|c|}{ Depth 3-5 m } \\
\hline & Mean (\%) & SD & Mean (\%) & SD & Mean (\%) & SD & Mean (\%) & SD \\
\hline Branchiura & 0.7 & 1.2 & 3.1 & 4.05 & 1.0 & 1.0 & 4.6 & 1.5 \\
\hline Chaoborus- $L$ & 73.0 & 14.7 & 53.4 & 19.67 & 78.0 & 12.9 & 36.1 & 19.5 \\
\hline Chaoborus- $P$ & 19.6 & 9.4 & 18.8 & 6.97 & 15.2 & 8.2 & 12.4 & 8.1 \\
\hline Chironomidae- $L$ & 0.1 & 1.0 & 3.7 & 4.87 & 0.2 & 0.4 & 24.1 & 14.0 \\
\hline Chironomidae-P & 0.0 & 0.0 & 1.3 & 2.01 & $a+0$ & 2.8 & 3.0 & 4.3 \\
\hline fish 5-60 mm (TL) & 3.0 & 3.7 & 2.6 & 2.94 & $\sqrt{2}$ & 3.6 & 6.2 & 4.2 \\
\hline Hydracarina & 3.6 & 4.0 & 17.2 & 11.52 & W & 1.0 & 13.6 & 7.5 \\
\hline
\end{tabular}

L, larvae; $P$, pupae.

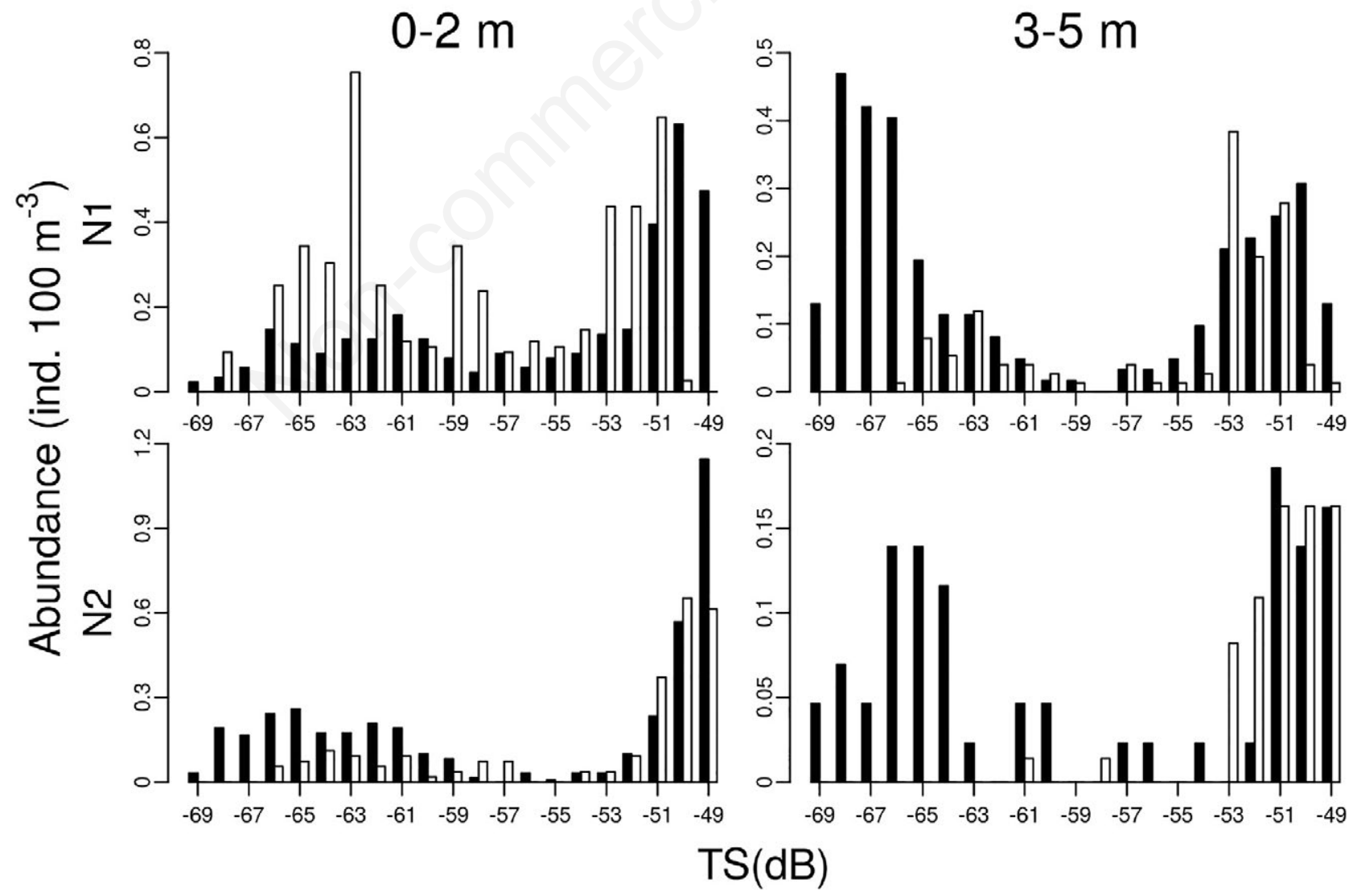

Fig. 4. TS distribution of the acoustically detected targets and fish catch of trawl. Acoustic $38 \mathrm{kHz}$ (black histograms) and fish sizes captured by the trawl converted into TS (white histograms) at the $38 \mathrm{kHz}$ frequency. 


\section{Comparison between acoustic and trawling results}

The logarithmic abundance estimates of Chaoborus by both methods (120 kHz echosounding and trawling) were not statistically different when using a Kolmogorov Smirnov paired test $(\mathrm{df}=24, \mathrm{P}>0.05)$. However, inspecting the $1: 1$ regression revealed the estimated acoustic abundance to be lower, especially in the zones where the abundance of trawl catch was the highest (Fig. 7).

Tab. 3. Mean size (mm) and standard deviation (SD) of the invertebrates and fish caught by the trawl.

\begin{tabular}{|c|c|c|c|c|c|c|c|c|}
\hline \multirow[t]{3}{*}{ Category } & \multicolumn{4}{|c|}{ Night 1} & \multicolumn{4}{|c|}{ Night 2} \\
\hline & \multicolumn{2}{|c|}{ Depth 0-2 m } & \multicolumn{2}{|c|}{ Depth 3-5 m } & \multicolumn{2}{|c|}{ Depth 0-2 m } & \multicolumn{2}{|c|}{ Depth 3-5 m } \\
\hline & Mean (mm) & SD & Mean (mm) & SD & Mean (mm) & SD & Mean (mm) & SD \\
\hline Branchiura & 6.0 & 0.4 & 6.0 & 0.5 & 5.0 & 0.3 & 5.0 & 0.3 \\
\hline Chaoborus-L & 9.5 & 0.4 & 9.0 & 0.4 & 9.0 & 0.3 & 9.0 & 0.3 \\
\hline Chaoborus- $P$ & 6.0 & 0.6 & 6.5 & 0.2 & 6.0 & 0.1 & 6.0 & 0.4 \\
\hline Chironomidae-L & 9.0 & 0.0 & 8.5 & 0.4 & 8.5 & 0.2 & 8.0 & 0.1 \\
\hline Chironomidae- $P$ & 0.0 & 0.0 & 6.0 & 0.3 & 5.5 & 0.8 & 5.5 & 0.1 \\
\hline fish 5-60 mm (TL) & 23.5 & 7.5 & 29.0 & 10.5 & 32.0 & 13.8 & 44.0 & 4.8 \\
\hline Hydracarina & 1.0 & 0.0 & 1.0 & 0.0 & 1.0 & 0.0 & 1.0 & 0.0 \\
\hline
\end{tabular}

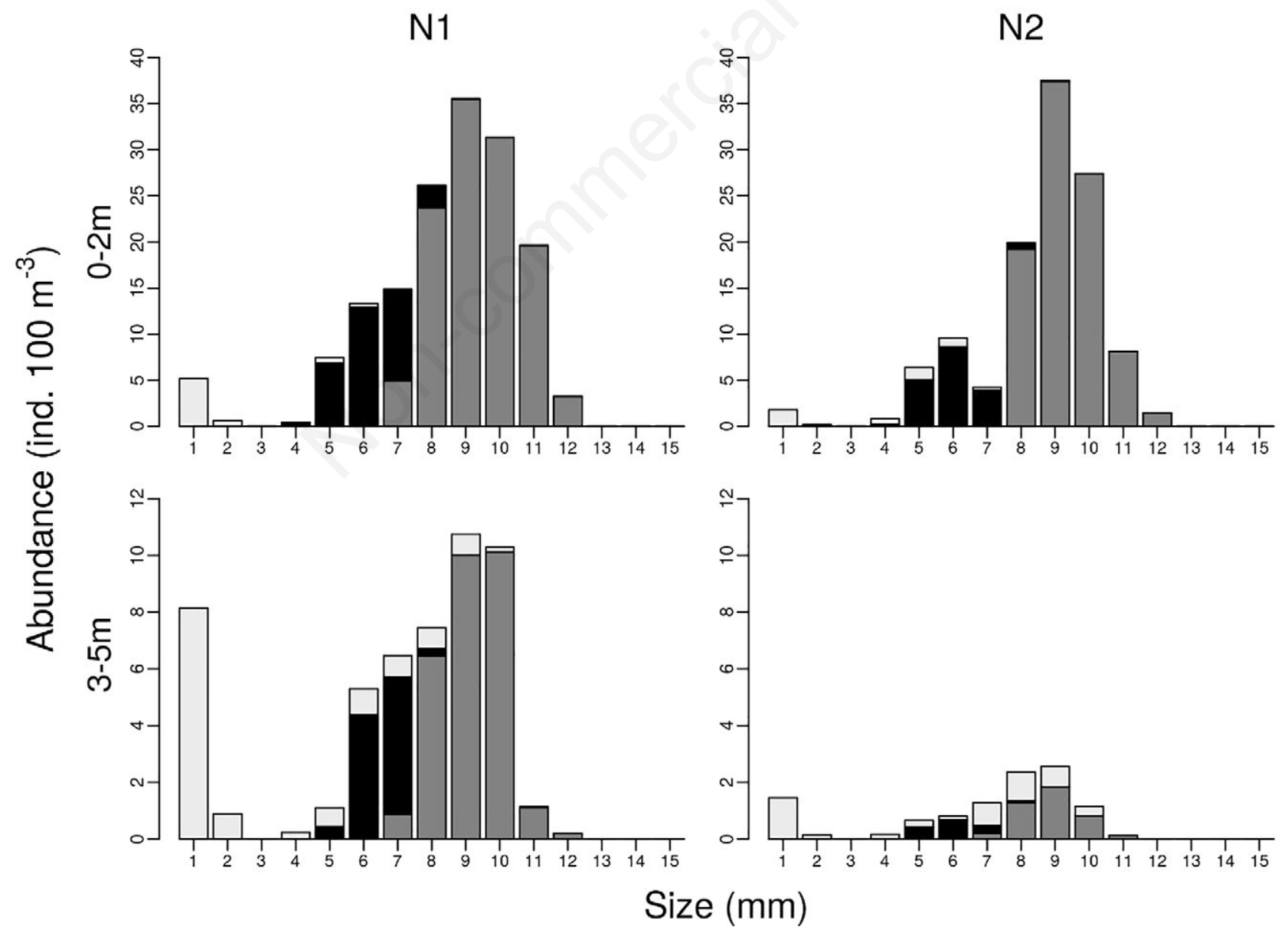

Fig. 5. The size distribution of invertebrates caught by ichthyoplankton trawl. Gray histograms indicate Chaoborus larvae, black Chaoborus pupae and light grey "other invertebrates". 


\section{DISCUSSION}

The mobile upward-looking echosounding methodology can record Chaoborus and juvenile fish near the water surface reasonably well. The $120 \mathrm{kHz}$ frequency can efficiently record Chaoborus larvae or pupae, which can bias the hydroacoustic estimates of fish in waterbodies. The size distributions of the ichthyoplankton trawl catch and $120 \mathrm{kHz}$ acoustic records showed a similar peak corresponding to the size of Chaoborus - the most abundant pelagic animal reflecting the echoes with good signal-to-noise ratio of some $10 \mathrm{~dB}$

Chaoborus larvae dominated night trawl samples mainly in the upper surface layer and very similar densities were recorded in $120 \mathrm{kHz}$ acoustic results. Knudsen et al. (2006) found that using the $200 \mathrm{kHz}$ frequency Chaoborus larvae had a TS of about $-65 \mathrm{~dB}$ Another group of targets with an overlapping TS range

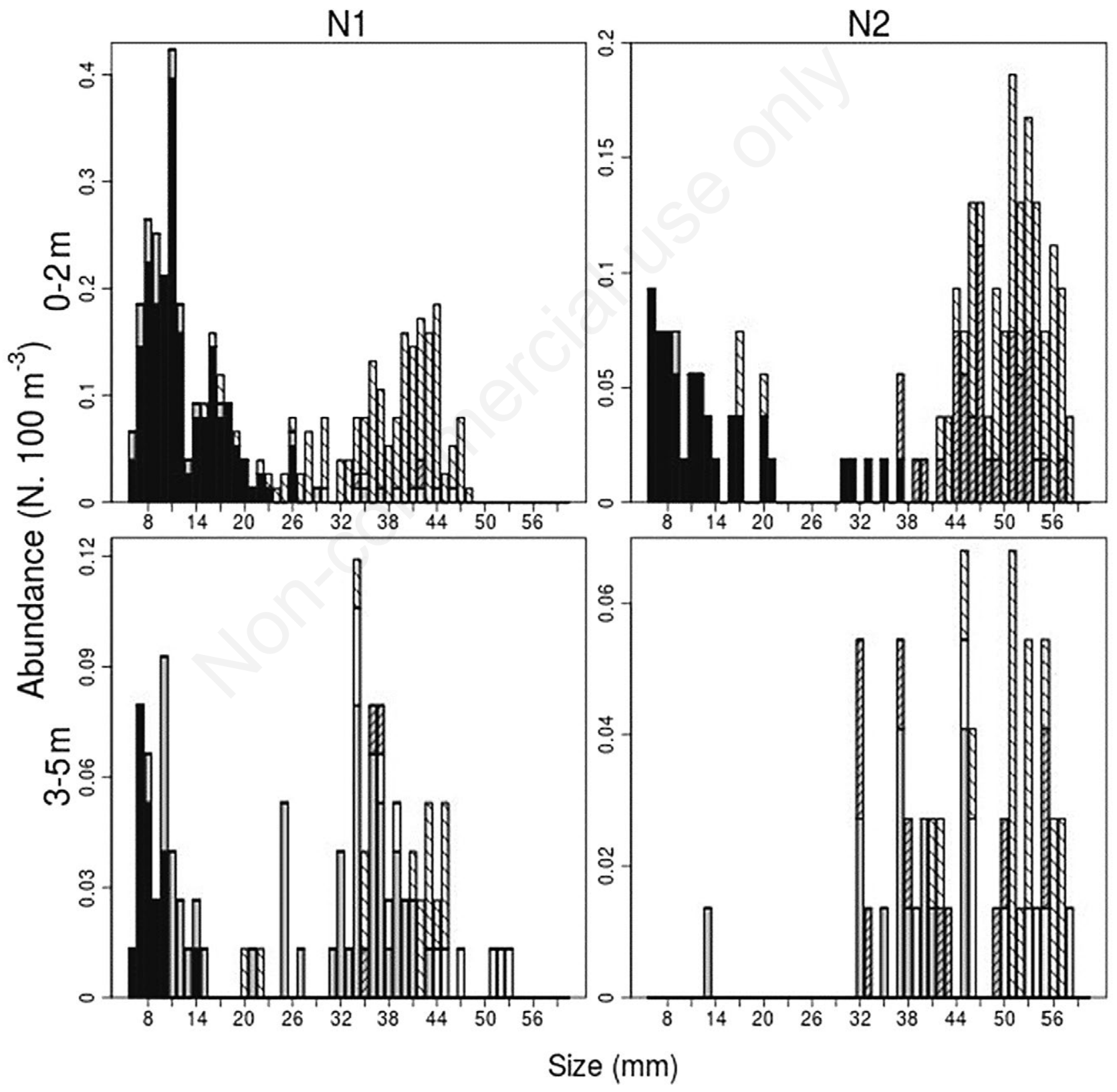

Fig. 6. Size and species structure of fish catch of the trawl. Black indicate Alburnus alburnus, grey Perca fluviatilis, white stripes Rutilus rutilus, grey stripes Abramis brama, white Stizostedion lucioperca. 
are Chironomids pupae with a TS range of -77 to $-65 \mathrm{~dB}$ (Kubečka et al., 2000). They have a complex of tiny gas hollows (thoracic horns) with hydrostatic functions (Langton, 1995). However, in the ichthyoplankton trawl, we recorded the proportion of Chironomids as only about 2-3 percent of all caught invertebrates, especially at the deeper layer. For this reason, Chironomids pupae hardly influence the results.

Chaoborus larvae showed a reduction in their average size (about $0.5 \mathrm{~mm}$ ) between two sampling nights. Size reduction from spring to autumn is also reported by other authors (Eckmann, 1998; Knudsen et al., 2006). The reason behind decreased size is most likely the growth of very small I-II instar larvae to observable size between surveys and possible emergence of large IV instar larvae. Prchalová et al. (2003) found that Chaoborus larvae and pupa have a TS in the range between -70 to $-64 \mathrm{~dB}$ in the $120 \mathrm{kHz}$ transducer. This partly corresponds to our results. However, our TS range is larger here probably because the mentioned study was conducted in tropical Thailand in February and only small individuals could occur or different species of Chaoborus may have been present. Several observations with an echosounder using a higher frequency of $200 \mathrm{kHz}$ suggest slightly higher range of modal TS -64 to -60 dB (Jones and Xie, 1994; Knudsen et al., 2006; Bezerra-Neto et al., 2012). A higher frequency is likely to be more sensitive for recording small targets, so the TS of Chaoborus may be higher with a $200 \mathrm{kHz}$ echosounder compared to a $120 \mathrm{kHz}$ one.

From Fig. 3 the acoustic size range of Chaoborus is

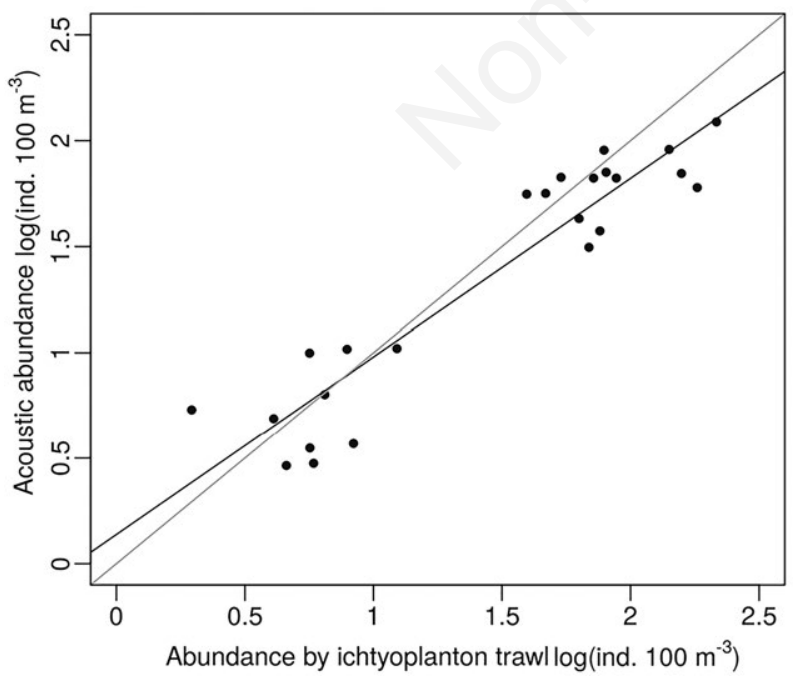

Fig. 7. The relationship between Chaoborus abundance estimates by the trawl and by $120 \mathrm{kHz}$ echo sounder (targets from -70 to $-55 \mathrm{~dB}$ ). The fitted linear regression equation was $\mathrm{y}=0.8420 * \mathrm{x}+0.1381$, coefficient of determination $\mathrm{R}^{2}=0.88$. considerably smaller than that of the older YOY fish cohort. The size of the smaller fish cohort from summer spawning (reported by Hladík and Kubečka, 2003; Čech et al., 2012), however, overlaps with the size of Chaoborus both physically and acoustically in the 120 $\mathrm{kHz}$ frequency. It is only possible to distinguish the large cohorts of juvenile fish with the recommended threshold $-55 \mathrm{~dB}$ or about $30 \mathrm{~mm}$ fish length based on the TS.

At $38 \mathrm{kHz}$, which is not sensitive to Chaoborus (Jones and Xie, 1994; Knudsen et al., 2006), we recorded a reasonable agreement between the acoustic and trawling densities (Fig. 4) of the cohort of fish fry larger than -55 $\mathrm{dB}$ The smaller size groups apparently contained a mixture of small fish from later spawning, invertebrates and possibly other targets. These were mainly present in the deeper 3-5 m layer (Fig. 4). Invertebrates other than Chaoborus such as parasitic Branchiura, Chironomidae or water mites Hydracarina were more abundant in the deeper layer.

Ichthyoplankton trawl with the mesh size $1 * 1.35 \mathrm{~mm}$ is not a traditional method for sampling Chaoborus. It was found rather quantitative for sampling fish larvae (Jůza et al., 2010). In our case it was used because the presence of targets of -70 to $-60 \mathrm{~dB}$ was recorded vastly in up looking records in the year previous to the survey (Baran et al., unpublished data). We expected to find fish larvae in the open water of the reservoir and this was the reason for the trawl selection. Some smaller slim invertebrates might have been lost through the meshes of the trawl. These losses are unlikely to be significant as many even smaller invertebrates were retained (Fig. 5). Also our mean sizes of Chaoborus are similar to sizes reported in similar studies (Eckmann, 1998; Knudsen and Larsson, 2009). On the other hand, $2 \times 2 \mathrm{~m}$ trawl is a robust sampling tool which greatly reduces the chances of sampled invertebrates to escape.

The acoustically estimated abundance of Chaoborus sized tracks was lower than trawl catch, especially in places where both methods recorded the highest abundance of Chaoborus larvae. The low abundance of Chaoborus larvae allowed us to use a trace counting method that required well detected traces of target individuals. Differences between density estimates by echo sounding and trawling can occur for at least two reasons. First, the method used to process the acoustic data by track counting does not enable the distinguishing between multiple overlapping targets that may occur at a higher abundance (Kocovsky et al., 2013; Baran et al., 2017). Second, some discrepancies between hydroacoustics and trawling results can be caused by the fact that despite the two sampling boats following very similar trajectories, it was not possible to concurrently sample the same volume of water by the two methods and horizontal distribution of Chaoborus larvae and fish was 
not homogenous. Possible solution of the first problem is the echointegration of entire invertebrate signal. The main problem with this approach is the need to use "upper threshold" to eliminate all fish targets from the record. Integrating any fish echo into the invertebrate record would lead to huge overestimation of density and can bias the results heavily. At this stage the application of "upper threshold in echo-integration" is not used routinely and is rather subjective so we decided to base our results on track counting. The advantage of track counting is that we are relatively sure that everything counted were the targets of interest.

\section{CONCLUSIONS}

The present study demonstrates the applicability of the mobile upward-looking hydroacoustic system to survey Chaoborus. The indisputable advantage of this system is the monitoring of juvenile fish and Chaoborus near the surface in stratified artificial lakes or natural lakes in the same record. Data obtained with the $120 \mathrm{kHz}$ frequency echosounder confirms that this frequency, primarily used to study fish, is capable of studying Chaoborus as well. Using the lower frequency of $38 \mathrm{kHz}$ offers the potential separation of a very small cohort of fish (6-20 mm TL) from Chaoborus larvae when the investigation of such extreme application is needed. Later in the ontogeny it is possible to use also the $120 \mathrm{kHz}$ frequency, however, the TS thresholds over $-60 \mathrm{~dB}$ are needed to distinguish fish from Chaoborus larvae. In our case, the estimation juvenile fish of over $30 \mathrm{~mm}$ was easy and safe.

\section{ACKNOWLEDGMENTS}

We thank L. Kočvara and Z. Prachař for help with data collection, L. Vebrova for processing ichthyoplankton catches and V. Děd for help with figures as well as the FishEcu team (www.fishecu.cz) for critical reading of the manuscript. The work was supported from ERDF/ESF project Biomanipulation as a tool for improving water quality of dam reservoirs (No. CZ.02.1.01/0.0/0.0/ 16_025/0007417) and project CZ.1.05/3.1.00/10.0214 technology transfer. R. Baran was supported by the project Grant Agency of the University of South Bohemia - project GAJU 158/2016/P. Leslie Tse kindly corrected the English of the manuscript. The valuable input of two anonymous reviewers is highly appreciated.

\section{REFERENCES}

Baran R, Jůza T, Tušer M, Balk H, Blabolil P, Čech M, Draštík V, Frouzová J, Jayasinghe AD, Koliada I, Mrkvička T, Muška M, Ricard D, Sajdlová Z, Vejř́ik L, Kubečka J, 2017.
A novel upward-looking hydroacoustic method for improving pelagic fish surveys. Sci. Rep. 7:4823.

Bezerra-Neto JF, Brighenti LS, Santos Teixeira De Mello AN, Pinto-Coelho RM, 2012. Hydroacoustic assessment of fish and Chaoborus (Diptera-Chaoboridae) distribution in three Neotropical lakes. Acta Limnol. Bras. 24:18-28.

Burrows M, Dorosenko M, 2014. Rapid swimming and escape movements in the aquatic larvae and pupae of the phantom midge Chaoborus crystallinus. J. Exp. Biol. 217:2468-2479.

CEN, 2014 Water quality - Guidance on the estimation of fish abundance with mobile hydroacoustic methods. EN 15910:2014. European Committee for Standardization, Brussels.

Čech M, Vejř́ik L, Peterka J, Říha M, Muška M, Jůza T, Draštík V, Kratochvíl M, Kubečka J, 2012. The use of artificial spawning substrates in order to understand the factors influencing the spawning site selection, depth of egg strands deposition and hatching time of perch (Perca fluviatilis L.). J. Limnol. 71:170-179.

Draštík V, Godlewska M, Balk H, Clabburn P, Kubečka J, Morrissey E, Hateley J, Winfield IJ, Mrkvička T, Guillard J, 2017. Fish hydroacoustic survey standardization: A step forward based on comparisons of methods and systems from vertical surveys of a large deep lake. Limnol. Oceanogr.Meth. 15:836-846.

Eckmann R, 1998. Allocation of echo integrator output to small larval insect (Chaoborus sp.) and medium-sized (juvenile fish) targets. Fish. Res. 35:107-113.

Foote KG, Knudsen HP, Vestnes G, MacLennan DN, Simmonds EJ, 1987. Calibration of acoustic instruments for fish density estimation: a practical guide. ICES Coop. Res., Charlottenlund: $57 \mathrm{pp}$.

Frouzová J, Kubečka J, 2004. Changes of acoustic target strength during juvenile perch development. Fish. Res. 66:355-361.

Hladík M, Kubečka J, 2003. Fish migration between a temperate reservoir and its main tributary. Hydrobiologia 504:251-266.

Jones IS, Xie JH, 1994. A sound scattering layer in a fresh water reservoir. Limnol. Oceanogr. 39:443-448.

Jůza T, Čech M, Kubečka J, Vašek M, Peterka J, Matěna J, 2010. The influence of the trawl mouth opening size and net colour on catch efficiency during sampling of early fish stages. Fish. Res. 105:125-133.

Jůza T, Vašek M, Kratochvíl M, Blabolil P, Čech M, Draštík V, Frouzová J, Muška M, Peterka J, Prchalová M, Říha M, Tušer M, Kubečka J, 2013. Chaos and stability of age-0 fish assemblages in a temperate deep reservoir: unpredictable success and stable habitat use. Hydrobiologia 724:217-234.

Jůza T, Vašek M, Kubečka J, Sed’a J, Matěna J, Prchalová M, Peterka J, ̌̌íha M, Jarolím O, Tušer M, Kratochvíl M, Čech M, Draštík V, Frouzová J, Hohausová E, Žaloudík J, 2009. Pelagic underyearling communities in a canyon-shaped reservoir in late summer. J. Limnol. 68:304-314.

Knudsen FR, Larsson P, Jakobsen PJ, 2006. Acoustic scattering from a larval insect (Chaoborus flavicans) at six echosounder frequencies: Implication for acoustic estimates of fish abundance. Fish. Res. 79:84-89.

Kocovsky PM, Rudstam LG, Yule DL, Warner DM, Schaner T, Pientka B, Deller JW, Waterfield HA., Witzel LD, Sullivan PJ, 2013. Sensitivity of fish density estimates to standard 
analytical procedures applied to Great Lakes hydroacoustic data. J. Great Lakes Res. 39:655-662.

Kubečka J, Frouzová J, Čech M, Peterka J, Ketelaars HAM, Wagenwoort AJ, Papáček M, 2000. Hydroacoustic assessment of pelagic stages of freshwater insects. Aquat. Living Resour. 16:325-331.

Lagergren R, Leberfinger K, Stenson J a. E, 2008. Seasonal and ontogenetic variation in diel vertical migration of Chaoborus flavicans and its effect on depth-selection behavior of other zooplankton. Limnol. Oceanogr. 53:1083-1092.

Langton PH, 1995. The pupa and events leading to eclosion, $\mathrm{p}$. 169-193 In: P.D. Armitage, P.S. Cranston and L.C.V Pinder (eds.), The Chironomidae: Biology and ecology of nonbiting midges. Springer, Dordrecht.

Love RH, 1977. Target strength of an individual fish at any aspect. J. Acoust. Soc. Am. 62:1397.

Malinen T, Tuomaala A, Peltonen H, 2005. Hydroacoustic fish stock assessment in the presence of dense aggregations of Chaoborus larvae. Can. J. Fish. Aquat. Sci. 62:245-249.

Prchalová M, Draštík V, Kubečka J, Sricharoendham B, Schiemer F, Vijverberg J, 2003. Acoustic study of fish and invertebrate behavior in a tropical reservoir. Aquat. Living Resour. 16:335-321.
R Development Core Team, 2015. R Foundation for Statistical Computing. Vienna.

Řiha M, Ricard D, Vašek M, Prchalová M, Mrkvička T, Jůza T, Čech M, Draštík V, Muška M, Kratochvíl M, Peterka J, Tušer M, Sed'a J, Blabolil P, Bláha M, Wanzenböck J, Kubečka J, 2015. Patterns in diel habitat use of fish covering the littoral and pelagic zones in a reservoir. Hydrobiologia 747:111-131.

Simmonds EJ, MacLennan DN, 2005. Fisheries acoustics: Theory and practice. Blackwell Publ. Ltd, Oxford: 456 pp.

Taskinen S, Warton DI, 2013. Robust tests for one or more allometric lines. J. Theor. Biol. 333:38-46.

Teraguchi S, 1975. Correction of negative buoyancy in the phantom larva, Chaoborus americanus. J. Insect Physiol. 21:1659-1670.

Vinni M, Lappalainen J, Malinen T, Peltonen H, 2004. Seasonal bottlenecks in diet shifts and growth of smelt in a large eutrophic lake. J. Fish Biol. 64:567-579.

Voss S, Mumm H, 1999. Where to stay by night and day: Sizespecific and seasonal differences in horizontal and vertical distribution of Chaoborus flavicans larvae. Freshwater Biol. 42:201-213. 